\title{
Choosing from Behind a Veil of Ignorance in India
}

\author{
Fredrik Carlsson ${ }^{\mathrm{A}}$ \\ Gautam Gupta $^{\mathrm{B}}$ \\ Olof Johansson-Stenman ${ }^{\mathrm{C}}$
}

\author{
Working Papers in Economics no. 72 \\ June 2002 \\ Department of Economics \\ Göteborg University
}

\begin{abstract}
Social inequality aversion is measured through a veil-of-ignorance experiment with Indian students. The median relative risk aversion is found to be quite high, about 3, and independent caste.
\end{abstract}

Key words: Veil of ignorance, inequality aversion, risk aversion, caste

JEL-classification: C91, D63

\footnotetext{
This paper has benefited from Gautam Guptas stay as a visiting research at the Environmental Economics Unit at Göteborg University and financial support from the Swedish International Development Agency (SIDA). Financial support from the Swedish Agency for Innovation Systems is also gratefully acknowledged.

A Department of Economics, Göteborg University, Box 640, SE-40530 Göteborg, Sweden. Tel: + 4631 7734174, e-mail: Fredrik.Carlsson@economics.gu.se

${ }^{B}$ Department of Economics, Jadavpur University, Kolkata-700 032, India

${ }^{\mathrm{C}}$ Department of Economics, Göteborg University, Box 640, SE-40530 Göteborg, Sweden. Tel: + 4631

7732538, e-mail: olof.johansson@economics.gu.se
} 


\section{Introduction}

The concept of choosing from behind a veil of ignorance, i.e. choosing between societies without knowing where you will be placed or what characteristics you will have in each society, to reflect goodness or fairness of societies, has proved very useful in theoretical economics (e.g. Vickrey 1947; Harsanyi 1955; Cremer and Pestieau 1998), political science (e.g. Frohlich and Oppenheimer 1992) and in moral philosophy (e.g. Rawls 1971). According to Harsanyi, the "ethical preferences" revealed from such choices would, under plausible conditions, reflect a utilitarian social welfare function. This is in sharp contrast to Rawls, who argued that people would only focus on the most unfortunate member of each society and would choose the society that is best for this member, in terms of some primary goods including income.

The veil-of-ignorance approach has received much less empirical interest. The only study, to our knowledge, that analyses the choice between different societies with different income distributions from behind a veil of ignorance is Johansson-Stenman et al. (2002). ${ }^{1}$ The present paper largely follows the experimental survey-design of that paper, but is adapted to an Indian context. The respondents make eight pair-wise choices between societies $A$ and $B$, given information about the highest, lowest and average income in each society, where both average income and the degree of inequality is always greater in $A$. The results enable us to estimate individual-specific parameters of relative risk aversion, which may be interpreted as social inequality aversion, and also to test econometrically the determinants behind these parameters. The Indian context is of particular interest because of the prevalence of the Caste system and its rather unequal income distribution.

\footnotetext{
${ }^{1}$ Frohlich and Oppenheimer (1992) report from several experiments where people instead choose between different distributive principles. There are of course other experimental approaches measuring attitudes to inequality, see e.g. Amiel and Cowell (1999). Johannesson and Gerdtham (1996) undertake a veil-ofignorance experiment on health-care inequality.
} 


\section{The Experiment}

364 students from Jadavpur University, Calcutta University, Kalyani University and Viswa Bharati University participated in the experiment. The first two universities are located in Calcutta city and the other two in rural areas in West Bengal. Participation was voluntary. The time for conducting each session varied between 20 and 30 minutes, and the students were given information both verbally and in printed form.

In order to create a veil-of-ignorance situation, the respondents were given the following information: "Imagine that in the future you have a grandchild, and you have the power to place him or her in a society of your choice." In this way, the respondents' own personal circumstances and environment are limited, although perhaps not eliminated. They were further told that they could not know the position of their future grandchild in the income structures of the given societies. The only information they received was the income distribution (and hence probability) of the future society. It was emphasised throughout the experiment that the societies were identical in all other respects; in particular, they were explicitly told that (i) all prices and available goods are exactly the same in the two societies, (ii) the societies are culturally and linguistically identical and (iii) government policy for affirmative action for scheduled (formerly known as lower) caste people are the same as today.

We assume that individuals' preferences are given by the constant relative risk aversion (CRRA) utility function $u=y^{1-\rho} /(1-\rho)$, where $y$ is disposable income and $\rho$ the relative risk aversion, which is often interpreted as the social inequality aversion (e.g. Christiansen and Jansen 1978; Amiel et al. 1999). If the individual is risk neutral then $\rho=0$ whereas if $\rho \rightarrow \infty$ then the individual is extremely risk averse and is of the Rawlsian maxi-min type.

In both societies, the income distribution was described by a right-angled triangular distribution, with the highest probability density at the lowest income level. This income distribution is of course crude but fairly realistic for a society such as India, and much easier to comprehend than, say, a log-normal distribution. Special emphasis was put on 
carefully explaining the features of the triangular distribution, which was also presented in a graph.

The CRRA utility function together with this triangular distribution results in the following expression for expected utility:

$$
E(u)=\int_{y_{\min }}^{y_{\max }} \frac{y^{1-\rho}}{1-\rho} \frac{2\left(y_{\max }-y\right)}{\left(y_{\max }-y_{\min }\right)^{2}} d y=\frac{2}{\left(y_{\max }-y_{\min }\right)^{2}}\left[\frac{y_{\max }\left(y_{\max }^{2-\rho}-y_{\min }^{2-\rho}\right)}{(2-\rho)(1-\rho)}-\frac{\left(y_{\max }^{3-\rho}-y_{\min }^{3-\rho}\right)}{(3-\rho)(1-\rho)}\right]
$$

Given that the respondents choose in order to maximize expected utility, they are indifferent between two societies, $A$ and $B$, iff $E\left(u_{A}\right)=E\left(u_{B}\right)$. Using this condition we can the relative risk aversion parameter at which the individual is indifferent. ${ }^{2}$ For example, if the respondent is indifferent between society $A$, where income varies between 7,000 and 60,000 Rupees, and society $B$, where income varies between 3,000 and 100,000 Rupees, then it can be shown that $\rho \approx 2$. Consequently, if $A$ is chosen $\rho<2$ and vice versa.

\section{Results}

338 out of 364 responses were consistent, i.e. they did not contradict themselves, given the assumed utility function. The income distributions of the societies and the results are presented in Table 1. Society $A$ was always the same and was compared in a pair-wise manner with the eight $B$-societies.

\section{[Table 1]}

The median relative risk aversion is close to 3 , but about $20 \%$ went for the extreme Rawlsian prediction, while 5\% appear to like risk. These results are very similar to the ones for Swedish students in Johansson-Stenman et al. (2002), the main difference being a somewhat higher fraction of the Rawlsian kind of response in the present study.

\footnotetext{
${ }^{2}$ Although there is no algebraic solution, it is straightforward to solve for $\rho$ using standard numerical methods.
} 
Table 2 presents the results from an interval regression model with the estimated individual relative risk aversion as the dependent variable. The two groups with the highest relative risk aversion are grouped together, so at the upper extreme we have $\rho>8$.

\section{[Table 2]}

Individuals who are politically left wing do not have a significantly different level of risk (or inequality) aversion than others, but if the respondent's parents support the left wing then the risk aversion is significantly (around 1.1 units) higher. This may indicate that values are largely formed at childhood and will persist from then on. Most other significant parameters, including the ones associated with the students' main streams of study, can probably be attributed to differences in expected future income. It is well known that people tend to modify their ethical values in a self-serving manner (e.g. Babcock et al. 1996), so that, for example, people with higher incomes tend to consider income inequality to be a less serious social problem. Consequently, risk aversion increases with the respondents' own income which is probably because it is mainly students from poorer families who have to work and support themselves.

The coefficient for Scheduled Caste is highly insignificant. ${ }^{3}$ However, recall that the university students of our sample belong to the elite of the Scheduled Caste, implying that the result could have been quite different with another sample.

\section{Conclusion}

Students in our Indian sample are found to be rather risk (inequality) averse when choosing from behind a simulated veil of ignorance. These results are close to earlier ones obtained for Sweden. A large part of the econometrically explained heterogeneity between individuals can probably be attributed to self-serving bias.

\footnotetext{
${ }^{3}$ Even when we run the regression with only Scheduled Caste as an explanatory variable, the coefficient is still insignificant.
} 


\section{References}

Amiel, Y. and F. Cowell (1999), Thinking About Inequality, Cambridge: Cambridge University Press.

Amiel, Y., J. Creedy and S. Hurn (1999), Measuring attitudes towards inequality, Scandinavian Journal of Economics 101, 83-96.

Babcock, L., X. Wang and G. Loewenstein (1996), Choosing the Wrong Pond: Social Comparisons in Negotiations that Reflect a Self-Serving Bias, Quarterly Journal of Economics 111, 1-19.

Christiansen, V. and E. Jansen (1978), Implicit social preferences in the Norwegian system of indirect taxation, Journal of Public Economics 10, 217-45.

Cremer, H. and P. Pestieau (1998), Social insurance, majority voting and labor mobility, Journal of Public Economics 68, 397-420.

Frohlich, N. and J. A. Oppenheimer (1992), Choosing Justice, University of California Press.

Harsanyi, J. (1955), Cardinal Welfare, individualistic ethics, and interpersonal comparisons of utility, Journal of Political Economy 63, 309-21.

Johannesson, M. and U. Gerdtham (1996), A note on the estimation of the equalityefficiency trade-off for QALYS, Journal of Health Economics 15, 359-68.

Johansson-Stenman, O., F. Carlsson and D. Daruvala (2002), Measuring future grandparents' preferences for equality and relative standing, Economic Journal 112, $362-83$.

Rawls, J. (1971), A Theory of Justice, Cambridge Mass.: Harvard University Press.

Vickrey, W. (1945), Measuring marginal utility by reactions to risk, Econometrica 13, 21536. 
Table 1. Societies and descriptive results of the experiment.

\begin{tabular}{|l|r|r|r|r|r|}
\hline \multicolumn{1}{|c|}{ Society } & \multicolumn{1}{c|}{$\begin{array}{c}\text { Min } \\
\text { Income }\end{array}$} & \multicolumn{1}{c|}{$\begin{array}{c}\text { Mean } \\
\text { Income }\end{array}$} & \multicolumn{1}{c|}{$\begin{array}{c}\text { Max } \\
\text { Income }\end{array}$} & $\begin{array}{c}\text { Relative risk } \\
\text { aversion if } \\
\text { indifference }\end{array}$ & $\begin{array}{c}\text { Share of } \\
\text { respondents } \\
\text { who chose } A\end{array}$ \\
\hline Society $\mathrm{A}$ & 3000 & 35333 & 100000 & & 0.04 \\
\hline Society $\mathrm{B}_{1}$ & 10000 & 35333 & 86000 & $\rho=0$ & 0.07 \\
\hline Society $\mathrm{B}_{2}$ & 9470 & 33460 & 81442 & $\rho=0.5$ & 0.15 \\
\hline Society $\mathrm{B}_{3}$ & 8770 & 30987 & 75422 & $\rho=1$ & 0.25 \\
\hline Society $\mathrm{B}_{4}$ & 7000 & 24733 & 60200 & $\rho=2$ & 0.51 \\
\hline Society $\mathrm{B}_{5}$ & 5550 & 19610 & 47730 & $\rho=3$ & 0.67 \\
\hline Society $\mathrm{B}_{6}$ & 4250 & 15016 & 36550 & $\rho=5$ & 0.76 \\
\hline Society $\mathrm{B}_{7}$ & 3680 & 13002 & 31648 & $\rho=8$ & 0.80 \\
\hline Society $\mathrm{B}_{8}$ & 3000 & 10600 & 25800 & $\rho \rightarrow \infty$ & \\
\hline
\end{tabular}

Table 2. Interval regression estimates of relative risk aversion

\begin{tabular}{|l|r|r|r|}
\hline & \multicolumn{1}{l|}{ Coefficient } & \multicolumn{1}{l|}{ P-value } & \multicolumn{1}{l|}{ Mean } \\
\hline Intercept & 5.721 & 0.00 & \\
\hline $\begin{array}{l}\text { Equivalence scaled monthly per capita household income } \\
\text { (1000 rupees) }\end{array}$ & -0.188 & 0.01 & 4.03 \\
\hline Respondent's own income (1000 rupees) & & & \\
\hline Scheduled caste & 0.717 & 0.04 & 0.272 \\
\hline Muslim & -1.602 & 0.98 & 0.13 \\
\hline Support left wing party & -0.262 & 0.21 & 0.02 \\
\hline Parents support left wing party & 1.125 & 0.66 & 0.20 \\
\hline Main stream of study & & & \\
- Economics & -2.387 & 0.01 & 0.33 \\
$-\quad$ Natural science & -0.536 & 0.35 & 0.06 \\
$-\quad$ Technology & -1.582 & 0.01 & 0.30 \\
$-\quad$ Social science & -1.736 & 0.02 & 0.12 \\
\hline Sigma & 3.389 & 0.00 & \\
\hline
\end{tabular}

*Equivalence scale used: 0.9 one adult, 0.71 each additional adult and 0.61 each child.

${ }^{* *}$ Base case: Humanities. 